\title{
Spectrum Quantification of Radium Isotopes in Hydraulic Fracturing Wastes
}

\author{
Leong Ying ${ }^{1}$, Robert Brenna ${ }^{1}$, Richard Yuen ${ }^{1}$, Cory Hoskins ${ }^{2}$ \\ ${ }^{1}$ KLYTEC, New Jersey, USA \\ ${ }^{2}$ Advanced TENORM, Kentucky, USA
}

Email address:

leong.ying@klytec.com (L. Ying), robert.brenna@klytec.com (R. Brenna), richard.yuen@klytec.com (R. Yuen), choskins@advtenorm.com (C. Hoskins)

\section{To cite this article:}

Leong Ying, Robert Brenna, Richard Yuen, Cory Hoskins. Spectrum Quantification of Radium Isotopes in Hydraulic Fracturing Wastes. International Journal of Environmental Monitoring and Analysis. Special Issue: Clean Methods and Technologies for Hydraulic Fracturing. Vol. 3, No. 2-1, 2015, pp. 7-10. doi: 10.11648/j.ijema.s.2015030201.12

\begin{abstract}
Exploration of oil and natural gas from shale deposits can bring to the surface radioactivity. Naturally occurring Uranium-238 and Thorium-232 as part of their decay chains can produce radium isotopes, which are themselves precursors of radon gas. Due to the solubility of radium and its contaminated impact on the environments and health concerns, regulations on the levels of Ra226 and Ra228 in processed wastes have been enforced. Gamma spectroscopy is a methodology used to qualitatively identify these radium isotopes, but to quantitatively analyze the activity concentrations requires appropriate calibration procedures and energy peak selections.
\end{abstract}

Keywords: Hydraulic Fracturing, TENORM, Gamma Spectroscopy, Radium

\section{Introduction}

Technologically Enhanced Naturally Occurring Radioactive Material (TENORM) brought to the surface due to hydraulic fracturing in the exploration for oil and natural gas is of major environmental and health concerns [1,2]. Conference of Radiation Control Program Directors (CRCPD) has mandated their working group E-42: Task Force to Review the TENORM Aspects of the Oil and Gas Industry to release new suggested regulations to all the States with such industrial activities [3]. For effective regulations new technologies and advanced products will need to be implemented along with the necessary procedures and processes that industry has to adopt. The first commercially deployed mobile spectroscopic radiation inspection system with shielding for low-activity measurements of radium isotopes in hydraulic fracturing wastes was developed by Ying [4], and hereby referred to as a TENORM Analyzer. The instrument was subsequently used to test a variety of material contents including rock, soil and water samples extracted from the Marcellus shale basin [5].

The TENORM Analyzer detection device consists of a sodium iodide doped with thallium $\mathrm{NaI}(\mathrm{Tl})$ scintillation crystal coupled to a photomultiplier tube (PMT). The output signal pulse amplitude is proportional to the energy of the incident gamma-ray entering the scintillation detector. Spectroscopy is the ability to identify the electromagnetic energy spectrum and infer the physical properties of the emitting object under observation. In this case, the objects are samples of hydraulic fracturing wastes, and by identifying the unique gamma-ray signature across an energy spectrum ranging from few $\mathrm{keV}$ to $3 \mathrm{MeV}$, it is possible to infer the types of radioactivity of these tested samples. Figure 1 shows the complete TENORM Analyzer system with fully integrated hardware and software. To reduce the background radiation, the 2 in x 2 in $\mathrm{NaI}$ detector is housed inside a $0.5 \mathrm{in}$ thick lead shield. The top of the shield has a sliding door panel that allows samples to be loaded into the inner chamber on top of the detector. The outputs from the PMT are processed by a multi-channel analyzer (MCA), which places the counts of each detected gamma-ray into appropriate channels that are proportional to the measured energies, so higher energies are located into higher channel numbers. The numbers of counts in each channel are typically displayed on a compatible software program that with sufficient count statistics will generate a spectrum with identifiable peaks. To define the energy of each peak, the spectrum channels must be calibrated with known standard sources. Table 1 lists some common energy calibration sources. Due to the slight 
non-linearity of scintillation detectors [6], it is recommended that a gamma spectrum is calibrated with multiple known peaks to ensure an accurate channel to energy conversion over the full detection range. Once energy calibrated, the TENORM Analyzer can be used to test unknown samples and identify specific radioisotopes from the measured peaks in the energy spectrum.

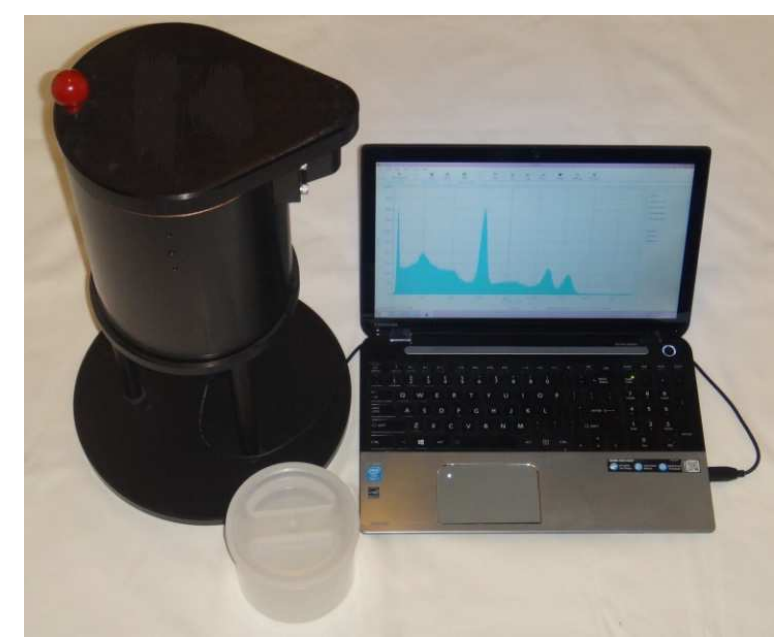

Figure 1. TENORM Analyzer with integrated hardware and software.

Table 1. Common energy calibration sources.

\begin{tabular}{ll}
\hline Isotopes & Main Energy Peaks $(\mathbf{k e V})$ \\
\hline $\mathrm{Na} 22$ & 511.0 \\
$\mathrm{~K} 40$ & 1460.8 \\
$\mathrm{Mn} 54$ & 834.8 \\
$\mathrm{Co} 57$ & 122.1 \\
$\mathrm{Co} 60$ & $1173.2,1332.5$ \\
$\mathrm{I} 131$ & 364.5 \\
$\mathrm{Ba} 133$ & $81.0,276.4,302.9,356.0,383.9$ \\
$\mathrm{Cs} 137$ & 661.6 \\
\hline
\end{tabular}

\section{Spectrum Analysis}

\subsection{Peak Identification}

Table 2 and 3 lists the natural radioactive decay series of U238 and Th232 and the main associated gamma-rays emitted by each isotope [7].

Table 2. U238 decay series.

\begin{tabular}{ll}
\hline Isotopes (Half-Life) & Gamma-Ray Energy (Intensity) \\
\hline U238 $\left(4.5 \times 10^{9} \mathrm{y}\right)$ & \\
Th234 $(24.1 \mathrm{~d})$ & $63.3 \mathrm{keV}(4.8 \%)$ \\
$\mathrm{Pa} 234(6.7 \mathrm{~h})$ & $883.2 \mathrm{keV}(9.6 \%), 946.0 \mathrm{keV}(13.4 \%)$ \\
$\mathrm{U} 234\left(2.4 \times 10^{5} \mathrm{y}\right)$ & \\
$\mathrm{Th} 230\left(7.4 \times 10^{4} \mathrm{y}\right)$ & \\
$\mathrm{Ra} 226(1,600 \mathrm{y})$ & $186.2 \mathrm{keV}(3.6 \%)$ \\
$\mathrm{Rn} 222(3.8 \mathrm{~d})$ & \\
$\mathrm{P} 218(3.1 \mathrm{~m})$ & \\
$\mathrm{Pb} 214(26 \mathrm{~m})$ & $295.2 \mathrm{keV}(19.2 \%), 352.0 \mathrm{keV}(37.2 \%)$ \\
$\mathrm{Bi} 214(19 \mathrm{~m})$ & $609.3 \mathrm{keV}(46.3 \%), 1120.3 \mathrm{keV}(15.1 \%)$ \\
$\mathrm{T} 1210(1.3 \mathrm{~m})$ & \\
$\mathrm{Pb} 210(22 \mathrm{y})$ & $46.5 \mathrm{keV}(3.9 \%)$ \\
$\mathrm{Bi} 210(5 \mathrm{~d})$ & \\
$\mathrm{Po} 210(138 \mathrm{~d})$ & \\
$\mathrm{Pb} 206$ & \\
\hline
\end{tabular}

Table 3. Th232 decay series.

\begin{tabular}{|c|c|}
\hline Isotopes (Half-Life) & Gamma-Ray Energy (Intensity) \\
\hline \multicolumn{2}{|l|}{ Th232 $\left(1.4 \times 10^{10} \mathrm{y}\right)$} \\
\hline \multicolumn{2}{|l|}{$\mathrm{Ra} 228(5.8 \mathrm{y})$} \\
\hline Ac228 (6.2hr) & $338.3 \mathrm{keV}(11.4 \%), 911.2 \mathrm{keV}(25.8 \%)$ \\
\hline Th228 (1.9y) & $84.4 \mathrm{keV}(1.2 \%)$ \\
\hline \multicolumn{2}{|l|}{$\operatorname{Ra} 224(3.7 d)$} \\
\hline \multicolumn{2}{|l|}{$\operatorname{Rn} 220$ (55.6s) } \\
\hline \multicolumn{2}{|l|}{ Po216 (0.1s) } \\
\hline $\mathrm{Pb} 212$ (10.6h) & $238.6 \mathrm{keV}(45.0 \%)$ \\
\hline $\operatorname{Bi} 212(60.6 \mathrm{~m})$ & $727.2 \mathrm{keV}(11.8 \%)$ \\
\hline \multicolumn{2}{|l|}{ Po212* $(0.3 \mu \mathrm{s})$} \\
\hline $\mathrm{T} 1208^{*}(3 \mathrm{~m})$ & $510.7 \mathrm{keV}(22.0 \%), 583.2 \mathrm{keV}(83.2 \%)$ \\
\hline \multicolumn{2}{|l|}{$\mathrm{Pb} 208$} \\
\hline \multicolumn{2}{|c|}{${ }^{*} \mathrm{Bi} 212$ decays $64 \%$ to Po 212 and $36 \%$ to T1208 } \\
\hline
\end{tabular}

If the decay series are in secular equilibrium, then all the associated isotopes in the chain will have the same activities, hence it is possible to analyze the daughter decay products to also determine the associated parent activities. However, when these NORM isotopes are removed from their deep underground reservoirs, the radium components due to their differing solubility can disturb the established equilibrium. And in the case of Ra226 the immediate daughter decay product is gaseous Rn222, which when allowed to escape into the atmosphere will also disturb the equilibrium chain. In laboratory-based radiochemical analysis of Ra226, the radium isotope is precipitated out of solution and purged of all radon gas before sealing. The half-life of Rn222 is 3.8 days, hence by waiting 21 days ( 5.5 half-lives) to re-accumulate the radon gas and re-establish equilibrium between Ra226 and Rn222, through alpha counting of the decays of Rn222 can be used to determine the activity of the parent isotope Ra226. Although this radiochemical methodology is adopted as a standard laboratory-certified test, the length of time to conduct the measurements make it prohibitive for many of the industry applications used to process and treat hydraulic fracturing wastes. Recent published research also indicates for high salinity wastewaters, this radiochemical method can produce very erroneous results [8]. The same article reported that gamma spectroscopy produced the most accurate results.

\subsection{Peak Quantification}

Once an energy peak is identified and associated with a known radioisotope, to quantify the radioactivity requires a further efficiency calibration of the system against standard sources of known activity concentration. This procedure is described in detail in reference [5].

A region-of-interest (ROI) is set around an energy peak associated with a radioisotope to be identified and quantified. For Ra226 the direct gamma energy of $186 \mathrm{keV}$ is used, although this decay has relatively low intensity compared to some of the other daughter decay products, there is no need to wait for secular equilibrium to be established to quantify the parent-to-daughter activities. Figure 2 illustrates the ROI (colored peak) set around the $186 \mathrm{keV}$ energy peak used to identify and quantify the activity concentration of Ra226 isotope in the tested samples. 


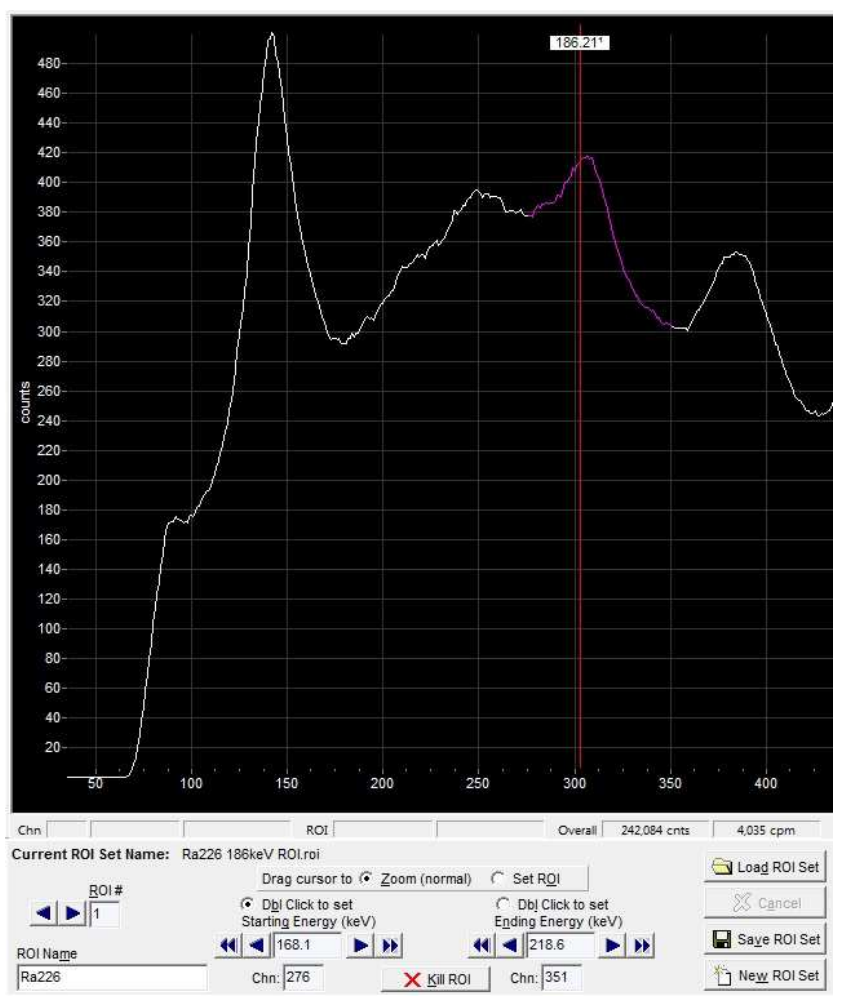

Figure 2. Software analysis with ROI set around Ra226 $186 \mathrm{keV}$ peak.

Since Ra228 do not have direct gamma-ray decays, an associated daughter decay product must be used to quantify this isotope by gamma spectroscopy method. The most appropriate daughter is Ac228 which is a direct decay off Ra228 with no intermediaries, and hence no long-term equilibrium is needed to be established. However, the main gamma decay energy for Ac228 is $338 \mathrm{keV}$, which due to the poor energy resolution of $\mathrm{NaI}$ scintillator (nominally $7 \%$ at Cs137 662keV) is difficult to resolve overlapping peaks with the intense $352 \mathrm{keV}$ gamma decay of $\mathrm{Pb} 214$. The next intense decay peak of Ac228 is $911 \mathrm{keV}(25.8 \%)$, but again due to poor resolution this peak also overlaps with the other Ac228 $965 \mathrm{keV}(5.0 \%)$ and $969 \mathrm{keV}(15.8 \%)$ energy peaks. However, by setting the ROI to capture all three peaks we instead increase the counting statistics for quantifying Ac228, and in turn Ra228. There is also an overlapping energy peak at $934 \mathrm{keV}$ associated with $\mathrm{Bi} 214$, but this relatively low intensity decay of $3 \%$ contributes a small statistic counting error. Table 4 lists the ROI parameters for quantification of Ra228/Ac228.

Table 4. Ac228 ROI parameters

\begin{tabular}{ll}
\hline Parameter & Values \\
\hline Left ROI marker & $840 \mathrm{keV}$ \\
Right ROI marker & $1010 \mathrm{keV}$ \\
Ac228 $1^{\text {st }}$ peak & $911.2 \mathrm{keV}(25.8 \%)$ \\
Ac228 $2^{\text {nd }}$ peak & $964.8 \mathrm{keV}(5.0 \%)$ \\
Ac228 $3^{\text {rd }}$ peak & $969.0 \mathrm{keV}(15.8 \%)$ \\
Bi214 peak & $934.1 \mathrm{keV}(3.0 \%)$ \\
\hline
\end{tabular}

\section{Data Comparison}

A collection of 30 samples from a waste treatment facility was measured with the TENORM Analyzer on-site, and the same samples sent to an external laboratory (Summit Environmental Technologies) for independent measurements using a State-approved and certified method. Figures 3 and 4 are the comparative results taken on all 30 samples for the quantification of Ra226 and Ra228 respectively. The plots show only the absolute values and trends, but do not include error bars on any of the data points.

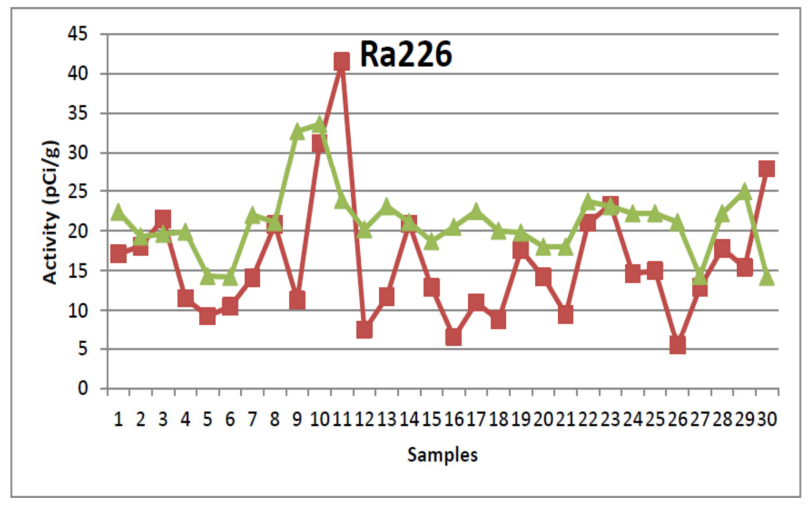

Figure 3. Ra226 comparison — TENORM Analyzer A Summit.

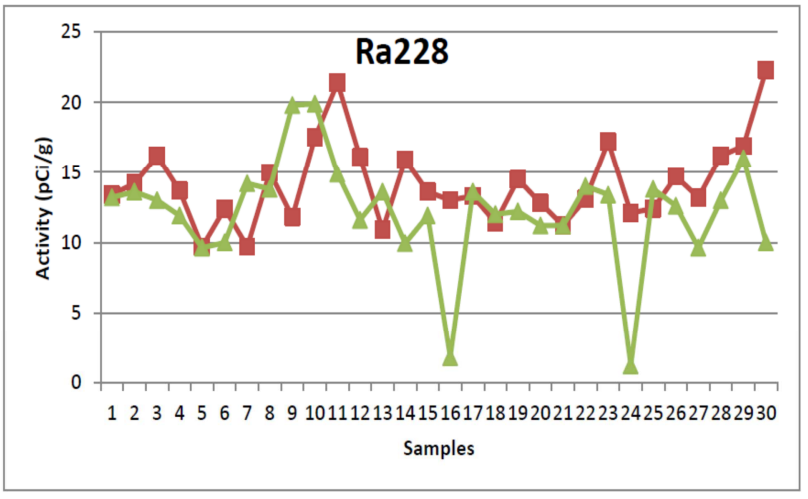

Figure 4. Ra228 comparison — TENORM Analyzer A Summit.

\section{Conclusion}

The TENORM Analyzer has undergone extensive field trials and tests as reported in previous referenced articles, and is now licensed by several States as an acceptable method for rapid screening of radium contamination levels in hydraulic fracturing wastes $[9,10]$. The statistical summing of multiple energy peaks in the quantification of Ra228 combined with appropriate calibration procedures produce consistent and accurate results.

\section{References}

[1] L. Ying, Analyzing TENORM in hydraulic fracturing wastes, International Journal of Environmental Monitoring and Analysis. Special Issue: Clean Methods and Technologies for Hydraulic Fracturing, vol. 3, no. 2-1, 2015, pp. 1-6, doi: 10.11648/j.ijema.2015030201.11. 
[2] N. R. Warner, C. A. Christie, R. B. Jackson, A. Vengosh, Impacts of shale gas wastewater disposal on water quality in western Pennsylvania, Environmental Science and Technology, vol. 47, 2013, pp. 11849-11857.

[3] Conference of Radiation Control Program Directors, The Suggested State Regulations for Control of Radiation: www.crcpd.org/SSRCRs/

[4] L. Ying, F. O'Connor, TENORM radiological survey of Utica and Marcellus Shale, Applied Radiation and Isotopes, vol. 80, 2013, pp. 95-98.

[5] L. Ying, F. O'Connor, J. Stolz, Scintillation gamma spectrometer for analysis of hydraulic fracturing waste products, Journal of Environmental Science and Health, vol. 50, Part A, 2015, pp. 499-503.

[6] J. L. Peeples, R. P. Gardner, Monte Carlo simulation of the nonlinear full peak energy responses for gamma-ray scintillation detectors, Applied Radiation and Isotopes, vol. 70, 2012, pp. 1058-1062.
[7] R. L. Heath, Scintillation Spectrometry Gamma-Ray Spectrum Catalogue, Idaho National Engineering and Environmental Laboratory, 1964, IDO Report: 16880-1.

[8] A. W. Nelson, D. May, A. W. Knight, et al., Matrix complications in the determination of radium levels in hydraulic fracturing flowback water from Marcellus shale, Environmental Science and Technology Letters, vol. 1, 2014, pp. 204-208.

[9] North Dakota Department of Health Radiation Control, Licensed TENORM Testing Facilities: www.ndhealth.gov/aq/rad/licensed_tenorm_testing.htm.

[10] Ohio Department of Health Bureau of Radiation Protection, Acceptable TENORM Analytical Methods for Radium-226 and Radium-228, 2014, pp. 1-5. 